\title{
Venom allergy treatment practices in Poland in comparison to guidelines: next edition of the national audit
}

\author{
Ewa Cichocka-Jarosz ${ }^{1}$, Marcin Stobiecki², Marita Nittner-Marszalska³, Urszula Jedynak-Wąsowicz ${ }^{1}$, Piotr Brzyski ${ }^{4}$; \\ Immunotherapy Section of the Polish Society of Allergology Working Group (PTA) ${ }^{5}$
}

${ }^{1}$ Department of Paediatrics, Jagiellonian University Medical College, Krakow, Poland

${ }^{2}$ Department of Clinical and Environmental Allergology, Jagiellonian University Medical College, Krakow, Poland

${ }^{3}$ Department of Internal Disease and Allergology, Medical University of Wroclaw, Wroclaw, Poland

4"Dziupla" Statistical Analysis, Krakow, Poland

${ }^{5}$ Immunotherapy Section of Polish Society of Allergology Working Group, Polish Society of Allergology, Lodz, Poland

Adv Dermatol Allergol 2019; XXXVI (3): 346-353

DOI: https://doi.org/10.5114/ada.2019.85642

\begin{abstract}
Introduction: Venom immunotherapy treatment (VIT) is the only causal treatment of hymenoptera venom anaphylaxis, which aims to provide long-lasting immunoprotection against severe reactions to subsequent stings.

Aim: To reassess the compliance of VIT procedures in the Polish allergy centres with the European guidelines.

Material and methods: A structured questionnaire survey conducted in all $33 \mathrm{VIT}$-centres. The response rate was $94 \%$. Results: The ultrarush initial protocol was the most common protocol $(71 \%, n=22)$, usually lasting for $3.5 \mathrm{~h}(50 \%$, $n=7)$. The most frequent $(36 \%, n=11)$ time interval from the initial to the first maintenance dose (MD) was 14 days, ranging from 7 to 35 days. All centres used an MD of $100 \mu \mathrm{g}$. The most frequent time interval between subsequent MDs was 4 weeks $(58 \%, n=18)$. Five years' of VIT was declared by $71 \%(n=22)$. Before the termination of treatment, more than half of the centres $(58 \%, n=18)$ performed slgE and almost half $(42 \%, n=13)$ performed skin tests. To confirm VIT efficacy, few centres $(26 \%, n=8)$ conducted the sting challenge. About half of centres provided the patients with an adrenalin auto-injector both at the time of initial diagnostics and at the end of treatment. More than half $(55 \%, n=17)$ used antihistamines in all patients. Almost half $(45 \%, n=14)$ declared to stop treatment with $\beta$-blockers and almost one fourth $(23 \%, n=7)$ discontinued angiotensin-converting-enzyme inhibitors.

Conclusions: In the most important procedures, there is a very high compliance with the guidelines. In the areas where the guidelines are not precise, we observed a large spread of results.
\end{abstract}

Key words: venom allergy, immunotherapy, national survey.

\section{Introduction}

Venom immunotherapy treatment (VIT) is the only causal treatment of hymenoptera venom anaphylaxis (HVA), which aims to provide long-lasting immunoprotection against severe reactions to subsequent stings. The rules of treatment to be the most safe and effective, are indicated by the up-dated evidence-based guidelines worldwide [1-4]. The first European guidelines on VIT were published by the European Academy of Allergy and Clinical Immunology (EAACI) in 1987, and updated in $2005[5,6]$, which initiated the development of national guidelines, including Polish [7], British [8] and others [9, 10]. An up-date of the EAACI VIT recommendations has been published in 2018 year [11, 12]. Even though the present-day recommen- dations should guarantee the optimal procedures in the treatment of HVA, current analysis shows that the actual practices differ in some aspects [13-16].

\section{Aim}

The aim of the study was to reassess the treatment procedures concerning HVA in Polish specialist centres and to evaluate their compliance with the European guidelines.

\section{Material and methods}

The study was conducted in 33 Polish allergy centres, which all specialize in the treatment of HVA patients. The

Address for correspondence: Marcin Stobiecki MD, PhD, Department of Clinical and Environmental Allergology, Jagiellonian University Medical College, 10 Śniadeckich St, 31-531 Krakow, phone: +48 501493 183, e-mail: marcin.stobiecki@uj.edu.pl

Received: 7.03.2018, accepted: 1.05.2018. 
survey was carried out by means of a structured questionnaire, which was an extended version of a questionnaire used in the first such study conducted in the United Kingdom [13] and in the previous Polish study [14].

The survey employed the computer assisted web interview (CAWI) method, using the LimeSurvey ${ }^{\oplus}$ software installed at the Jagiellonian University Medical College web server [17]. An email with an invitation to the study and a personalized link to the questionnaire, was sent to the head of each centre. In case of a lack of an answer, two email reminders were sent 1 week apart, followed up with a telephone reminder. The response rate was 94\% (31 centres answered), two centres did not fill out the questionnaire, one of which only performs diagnostics of HVA. Results are not supported by statistical tests because the paper presents real data.

\section{Results}

Forty two percent $(n=13)$ of Polish centres treated exclusively adults, $26 \%(n=8)$ dealt only with children, while $32 \%(n=10)$ of centres treated both age groups (Figure 1). The total number of VIT-treated patients in
2015 was 3,090, with an adult to child ratio of $5: 1$. In $94 \%(n=29)$ of centres, treatment was performed as an inpatient procedure).

\section{Venom preparation}

Two types of venom extracts are available in Poland: unpurified aqueous and depot extracts. During the updosing (UpD), most of the centres ( $87 \%, n=27)$ used only aqueous extracts, $3 \%(n=1)$ used only depot ones, while $10 \%(n=3)$ of centres work on both formulations. During the maintenance dose (MD), exclusively the aqueous venom preparations were used in $45 \%(n=14)$ of centres, followed by the depot extracts $(29 \%, n=9)$ and $26 \%(n=8)$ of centres used both types of extracts. The same extract, during both UpD and MD, was used in $48 \%(n=15)$ of the centres, while almost one sixth $(16 \%$, $n=5)$ switched from an aqueous extract to a depot one during the MD, one fourth $(26 \%, n=8)$ began with an unpurified aqueous extract and continued with the same, $10 \%(n=3)$ began with one of the two and continued only with the depot extract. Only $6 \%(n=2)$ changed the aqueous extract to the other.

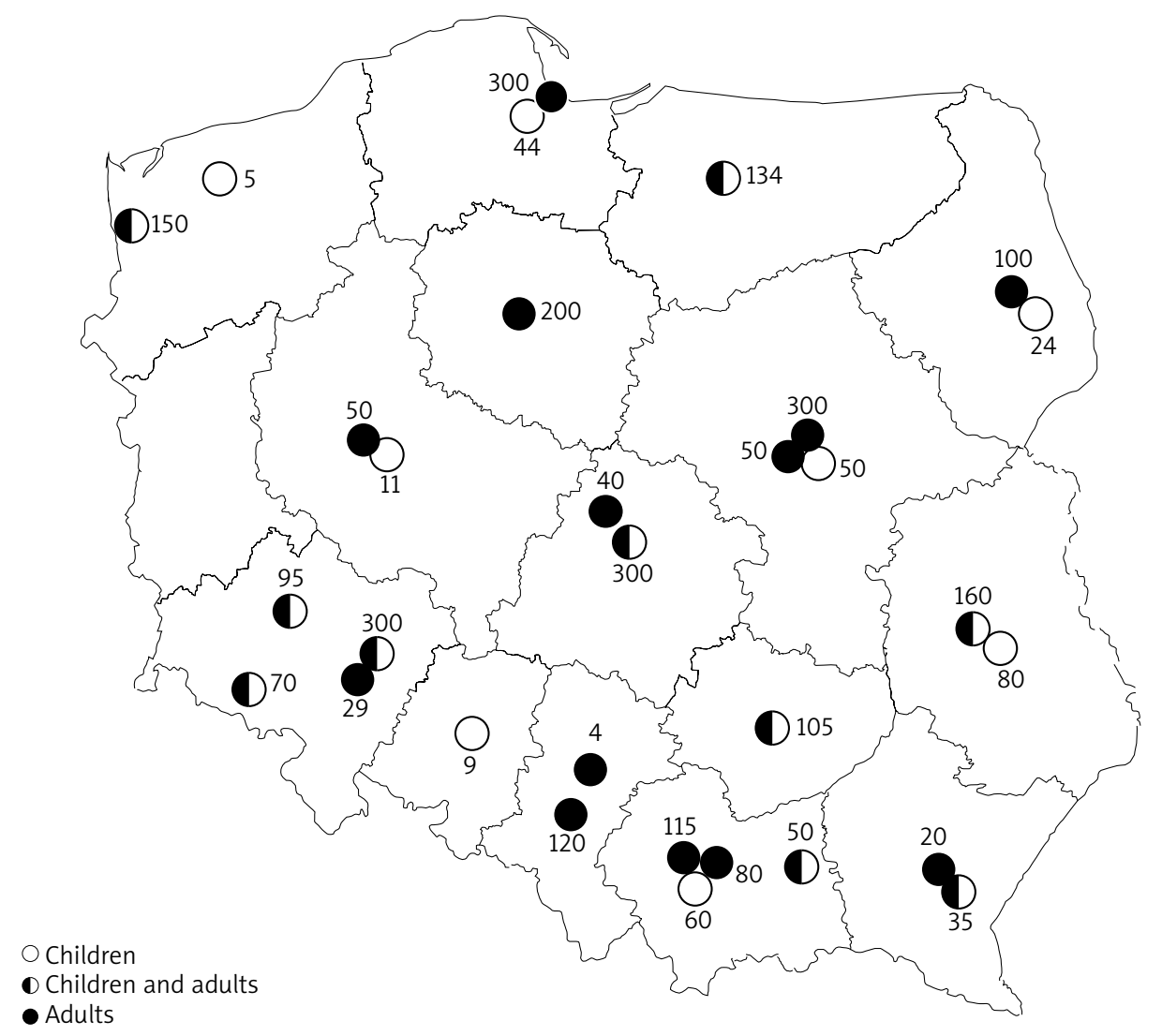

Figure 1. The location of the Hymenoptera venom allergy treatment centres, and number of patients diagnosed in particular centre in 2016 


\section{Initial treatment (up-dosing - UpD)}

The ultrarush (UR) protocol of one day was the most common treatment regimen used in $71 \%(n=22)$ of the centres, followed by the rush protocol of a few days $(16 \%, n=5)$ and the cluster protocol of a few weeks $(13 \%$, $n=4)$. None of the centres declared to use the conventional protocol. The reasons for the common application of the UR were: short duration of treatment (32\%, $n=10)$, rapid immunoprotection $(19 \%, n=6)$ and the economic aspect $(9 \%, n=3)$, including distance from the patient's place of living to the VIT centre.

The UR mostly lasted $3.5 \mathrm{~h}(50 \%, n=7)$ or $4 \mathrm{~h}(29 \%$, $n=4)$. According to all answers $(n=14)$, the duration varied from 3 to $8 \mathrm{~h}$. The cumulative dose of the venom extract in this protocol was $101.1 \mu \mathrm{g}(36 \%, n=6)$ or $111.0 \mu \mathrm{g}(23 \%$, $n=3$ ), respectively; though $1 / 3$ of centres did not respond to this question, including these administering protocols other than the UR protocols.

If the patient during the UPD VIT, despite the premedication with antihistamines, revealed systemic reactions of grades 2 to 4 according to the Mueller's classification, then most centres continued treatment by changing the protocol to another one $(70 \%, n=22)$, but few continued changing the protocol individually $(15 \%, n=5)$. Some discontinued immunotherapy providing the patient with an adrenalin auto-injector (AAI), or practiced other strategies (Table 1).

\section{Maintenance treatment (maintenance dose - MD)}

The most common time interval from UpD to the first MD was 14 days ( $36 \%, n=11)$, in $68 \%(n=21)$ of centres it was no longer than 15 days, while with respect to all answers, this period ranged from 7 to 35 days. All centres used an MD of $100 \mu \mathrm{g}$. The first MD was usually divided into $50+$ $50 \mu \mathrm{g}(74 \%, n=23)$, less frequently was applied as a single dose of $100 \mu \mathrm{g}(10 \%, n=3)$. There were also few patterns used by individual centres: $20+30+50 \mu \mathrm{g}(6 \%, n=2)$, $30+70 \mu \mathrm{g}$ and $20+40+40 \mu \mathrm{g}$ ( $3 \%$ each, $n=1$ ) or other schemes "depending on previous UR tolerance" $(3 \%, n=1)$.
The most frequent time interval between subsequent MDs was 4 weeks $(58 \%, n=18)$ regardless of the kind of venom preparation, followed by 6 weeks $(16 \%, n=5)$, and up to 8 weeks reported also by $16 \%(n=5)$. The 6 -week $M D$ intervals were over three times more frequently applied with the depot extract ( $24 \%$ of centres, $n=4$ ) than with the aqueous ones $(7 \%, n=1)$. Eight weeks were regarded as a maximum acceptable MD interval by $48 \%$ of centres $(n=15)$, followed by 6 weeks $(36 \%, n=11)$. A very few $(10 \%$, $n=3)$ centres accepted a maximum interval of 12 weeks.

\section{Treatment duration}

Over two thirds of centres $(71 \%, n=22)$ declared that they conduct VIT for exactly 5 years, followed by $29 \%(n=9)$ applying it for 3 to 5 years. Different lengths of treatment were declared by $81 \%(n=25)$ of the centres for patients with mastocytosis, and among them over half $(63 \%, n=$ 10) declared lifelong treatment of those patients. About one fourth of centres $(26 \%, n=8)$ used a different treatment duration in patients with an elevated baseline serum tryptase (bsT), however, $9 \%(n=3)$ of centres declared that they have not had any such patients. A different (no precised) treatment duration was mentioned by $3 \%(n=1)$ of the centres for beekeepers' families, and by $10 \%(n=3)$ of the centres for patients with cardiovascular disease.

\section{Assessment of treatment efficacy before its termination}

Before the termination of treatment, more than half of the centres ( $58 \%, n=18)$ performed venom specific IgE (slgE) while almost half $(42 \%, n=13)$ performed skin tests. In presence of positive results (either blood or skin tests), two thirds of the centres $(68 \%, n=21)$ did not extend the treatment period, $13 \%(n=4)$ of centres declared that they usually extend the treatment exclusively in patients with pre-treatment severe anaphylaxis, $3 \%$ $(n=1)$ in all patients irrespective of Mueller's grade, whereas 16\% $(n=5)$ depending on the following scenarios during VIT: positive sting challenge (SC) response,

Table 1. Management of patients with repeated systemic grade 2-4 reactions during the incremental dose of venom preparation, regardless of antihistamine treatment

\begin{tabular}{|c|c|c|}
\hline Alternative interventions & $N$ & Percent \\
\hline Change of protocol to the cluster one & 13 & 42 \\
\hline Change of protocol to the conventional one & 5 & 15 \\
\hline Change of protocol to the rush one & 2 & 6 \\
\hline Change of protocol to the ultrarush one & 2 & 6 \\
\hline Start VIT from the beginning with an individually chosen protocol aiming to accede maintenance dose over $100 \mu \mathrm{g}$ & 3 & 9 \\
\hline Continue treatment by lowering to the last well-tolerated dose & 2 & 6 \\
\hline Continue VIT combined with premedication with systemic corticosteroids & 1 & 3 \\
\hline Discontinuation of immunotherapy with a recommendation for the patient to apply AAI & 2 & 6 \\
\hline No answer & 1 & 3 \\
\hline
\end{tabular}


grade $2-4$ reaction due to a field sting or severe reaction to treatment venom preparation. To confirm VIT efficacy some of the centres conducted the SC regardless of the kind of the culprit insect $(10 \%, n=3)$ or only in case of a bee venom allergy $(13 \%, n=4)$. One centre $(3 \%, n=1)$ did not specify its criterion. No centre performed a SC more than once per patient. The evaluation of IgG4 was performed by $13 \%(n=4)$ of centres either during the treatment period or before its termination.

\section{Medication}

\section{Adrenaline auto-injector prescription}

About half of centres provided AAI to all patients referred for diagnostics regardless of severity of systemic reactions and a slightly smaller portion of the centres only to those patients who had a history of a pre-diagnostic anaphylaxis from 2 to 4 of Mueller's grades. In VITtreated patients, AAI was prescribed by most of centres regardless of the degree of an anaphylactic reaction. At the end of the VIT, half of the centres prescribed AAI to all their patients (Table 2). All centres provided AAI to every patient with mastocytosis, regardless of the effectiveness of the immunotherapy.

\section{Pre-treatment with antihistamines}

More than half of the centres used antihistamines in all patients during the initial protocol and almost half of the centres declared using them in all patients during the maintenance dose. A very few centres used those drugs in case of a systemic side reaction (SSR) (Table 3).

\section{Cardiovascular treatment}

Almost half $(45 \%, n=14)$ of the centres declared that they had stopped treatment with $\beta$-blockers and almost one fourth $(23 \%, n=7)$ discontinued angiotensin-converting-enzyme inhibitors (ACEI), while $3 \%(n=1)$ only reduced the ACEI dose before VIT introduction. Meanwhile, one third of centres $(29 \%, n=9)$ did not change the cardiovascular treatment.

\section{Discussion}

Presented data represent nearly the whole population of specialists applying VIT in Poland. The data are discussed with reference to the previous and current EAACl guidelines (Table 4) as well as in comparison to the British, French and previous Polish studies [13-16]. The European guidelines are intended for all countries, which are members of the EAACl and thus it is a disappointment that such a small number of national reports exist on the correspondence of real-life practice with the guidelines.

\section{VIT treatment organization}

In comparison to 2009, we observed both an increase in the number of specialist centres and in the number of centres treating both age groups [14]. Currently, about one third of Polish centres treat both children and adults, while in the UK only one fifth of the centres do [15]. Adult care centres dominate both in Poland and in the UK (42\% vs. 58\%), which corresponds with the higher prevalence of HVA in the older population [18]. The total number of patients treated with VIT in 2015 in Poland was just over 3,000 . Considering the average of systematic reactions to hymenoptera stings amongst the European adult population (3\% to $8.9 \%$ ) [18], and the population of Poland (approximately 38 millions) we can hypothesise that this type of allergy goes undiagnosed.

\section{Venom preparation and immunotherapy}

VIT is performed by the subcutaneous route and consists of an UpD phase when immunoprotection is achieved, and an MD phase, which is crucial for maintaining the long follow-up efficacy. The current and previous EAACI guidelines present four protocols, but do not indicate a specific protocol for the initial dose [6, 12]. Thus, Polish doctors often choose the initial protocol based on the bibliography data [19-22], their experience, opinion on safety and effectiveness of the protocol as

Table 2. Adrenaline autoinjector (AAI) prescription approach to hymenoptera venom allergic patients, at different phases of the treatment

\begin{tabular}{|c|c|c|c|}
\hline Clinical choice & $\begin{array}{l}\text { Prior to VIT (referred for diagnosis) } \\
\qquad N(\%)\end{array}$ & $\begin{array}{l}\text { During VIT } \\
\qquad N(\%)\end{array}$ & $\begin{array}{l}\text { After VIT } \\
\qquad N(\%)\end{array}$ \\
\hline All patients & $15(47)$ & $21(68)$ & $16(53)$ \\
\hline Only those with grade 2 to 4 anaphylactic reactions & $13(41)$ & $3(10)$ & $3(10)$ \\
\hline Only those with grade 3 to 4 severe anaphylactic reactions & $3(9)$ & $6(19)$ & $6(19)$ \\
\hline Frequently exposed to stinging and experiencing LLR & $1(3)$ & & \\
\hline In grade 1 reaction and parents' request & & $1(3)$ & $1(3)$ \\
\hline Only in individual cases; grade 4 , never stung during the VIT & & & $1(3)$ \\
\hline Sometimes yes (no explanations) & & & $1(3)$ \\
\hline No & & & $3(10)$ \\
\hline
\end{tabular}


well as economic factors (i.e. costs of the protocol or reimbursement regulations) [23].

In Poland we observed a growing preference for UpD immunotherapy ultrarush protocols (cumulative dose of $111.1 \mu \mathrm{g}$ by Muller or of $101.1 \mu \mathrm{g}$ by Birnbaum) [24, 25] (71\%

Table 3. Pre-treatment with antihistamines with respect to the treatment phase

\begin{tabular}{lcc}
\hline Clinical choice & $\begin{array}{c}\text { Initial } \\
\text { treatment } \\
\boldsymbol{N}(\%)\end{array}$ & $\begin{array}{c}\text { Maintenance } \\
\text { treatment } \\
\boldsymbol{N}(\%)\end{array}$ \\
\hline To all patients during VIT & $17(55)$ & $15(48)$ \\
\hline In cases of LLR after injection & $12(39)$ & $16(52)$ \\
\hline In cases of SSR after injection & $2(7)$ & $2(7)$ \\
\hline In all cases of atopy & $1(3)$ & $1(3)$ \\
\hline Asthma, cardiovascular diseases & - & $3(10)$ \\
\hline In majority of patients & - & $1(3)$ \\
\hline
\end{tabular}

vs. 58\% in 2009 [14]) as well as the lack in use of the conventional protocol. The UR protocol is the most commonly (60\%) reported by the French authors [16], while in the UK the most common protocol remains the conventional one (76\% vs. $92 \%$ during the previous study) $[13,15]$. This difference may arise from the fact that in Poland, VIT is performed as an in-hospital procedure, in the UK it is an outpatient one, whereas in France, UpD is given in inpatient and continued in outpatient settings $[15,16]$.

The EAACl guidelines of 2005 and 2017 do not specify the time interval between UpD and MD $[6,12]$. The only reference to the recommended time interval comes from the first EAACI guidelines on VIT [5] and from subcutaneous immunotherapy standards [26]. As a result of the audit, the areas in which the answers showed a large variance were identified (Table 4). They concern the duration of the UR protocol (from 3 to $8 \mathrm{~h}$ ) and the time interval between the completion of the UpD and the administration of the first dose of MD (from 7 to 35 days).

Table 4. A comparison of Polish practices of VIT with respect to the 2005 and 2017 EAACI guidelines

\begin{tabular}{|c|c|c|c|}
\hline Point for discussion & Polish VIT 2016 practices & $\begin{array}{l}\text { EAACI Guidelines } 2005 \\
\text { Bonifazi et al. }\end{array}$ & $\begin{array}{l}\text { EAACI Guidelines } 2017 \\
\text { Sturm et al. }\end{array}$ \\
\hline $\begin{array}{l}\text { Venom preparation vs. kind } \\
\text { of protocol }\end{array}$ & $\begin{array}{l}\approx 83 \% \\
3 \%\end{array}$ & \multicolumn{2}{|c|}{$\begin{array}{l}\text { Aqueous preparation for UpD with R/UR, depot for UpD with conventional } \\
\text { protocol }\end{array}$} \\
\hline UpD & $\begin{array}{l}3-8 \mathrm{~h} \\
6 \text { cum. doses from } 100 \text { to }\end{array}$ & \multicolumn{2}{|l|}{$\begin{array}{l}\text { Not precisely indicated by the guidelines } \\
\text { - Length of rapid }(U R, R) \text { protocols }\end{array}$} \\
\hline Change of protocol when & $111.1 \mu \mathrm{g}$ & & \\
\hline 2-4 SR during UpD & $81 \%$ & \multicolumn{2}{|l|}{ - Protocol of up-dosing at 2-4 SR } \\
\hline MD & $\begin{array}{l}100 \% \\
90 \% \\
100 \% \\
7 \text { to } 35 \text { days } \\
6 \text { schemes } \\
\text { - }\end{array}$ & \multicolumn{2}{|c|}{$\begin{array}{l}\text { Indicated by the guidelines: } \\
-100 \mu \mathrm{g} \\
\text { - Interval } \\
-3-5 \text { years treatment } \\
\text { Not precisely indicated by the guidelines: } \\
\text { - Interval from UpD to MD } \\
\text { - Fractioning of the first MD } \\
\text { - Protocol of increasing to } 200 \mu \mathrm{g}, \text { when react to field sting or venom } \\
\text { extract on VIT } \\
\text { - Anti-lgE dosing for premedication }\end{array}$} \\
\hline $\begin{array}{l}\text { Diagnostic tests before VIT } \\
\text { termination }\end{array}$ & $\approx 50 \%$ & \multicolumn{2}{|c|}{ Limited predictive value with regard to long-term protection after VIT } \\
\hline Sting challenge & $\approx 25 \%$ & $\begin{array}{l}\text { Before taking a decision on VIT } \\
\text { termination }\end{array}$ & If available as early as possible \\
\hline Supply with AAI & $\begin{array}{l}\approx 50 \% \text { before, during and } \\
\text { after VIT. } \\
100 \% \text { in severe reactors } \\
\text { and mastocytosis patients }\end{array}$ & $\begin{array}{l}\text { Patients allergic to hymenoptera } \\
\text { venoms should carry an emergency } \\
\text { kit for self-administration, especially } \\
\text { during the insect season }\end{array}$ & $\begin{array}{l}\text { In all mastocytosis patients } \\
\text { In all moderate to severe reactors } \\
\text { after terminating VIT if risk factors } \\
\text { for treatment failure are present }\end{array}$ \\
\hline $\begin{array}{l}\text { Pre-treatment with } \mathrm{H}_{1} \\
\text { antihistamines }\end{array}$ & $\approx 50 \%$ & $\begin{array}{l}\text { 1-2 days before VIT, to be continued } \\
\text { until the MD has been well } \\
\text { tolerated at least for } 3 \text { times }\end{array}$ & 1-2 h before MD, sometimes b.i.d. \\
\hline $\begin{array}{l}\text { Approach to cardiovascular } \\
\text { treatment before VIT } \\
\text { introduction }\end{array}$ & $\begin{array}{l}\text { Withdrawal: } \\
\approx 50 \% \beta \text {-blockers } \\
\approx 25 \% \mathrm{ACEl}^{8}\end{array}$ & $\begin{array}{l}\text { Substitution of } \beta \text {-blockers or ACEI } \\
\text { should be discussed }\end{array}$ & $\begin{array}{l}\text { No contraindications to continue } \\
\beta \text {-blockers. } \\
\text { Negative influence of ACEI might } \\
\text { be overestimated }\end{array}$ \\
\hline
\end{tabular}

UpD - up-dosing protocol, UR - ultrarush, $R$-rush, $S R$ - systemic reactions, MD - maintenance dose, AA - adrenaline autoinjector, b.i.d. - bis in die (twice a day), ACEI - angiotensine inhibitors. 
Differentiation is common, for example, French authors reported one month between UpD and the first MD [16].

In case of complications in the UpD VIT phase, according to the recommendations, doctors should continue VIT by restarting with a slower protocol. Sixty one percent of Polish centres followed this recommendation in the current study vs. $31 \%$ in the 2009 study [14]. There is a wide variation in behaviour in European countries; Poland is like France, however, the UK is different, where VIT is interrupted in such circumstances $[13,15,16]$. There is no good explanation for a very rare practice to accelerate the UpD protocol in case of complications.

There is a high compliance in Poland and other countries with the EAACI guidelines in respect to the recommended kind of the venom extract (aqueous, depot) vs. VIT protocol, the recommended time interval between subsequent MDs $[13,15,16]$ and nominal value of MD. However, single centres in Poland used depot preparations for cluster or rush/ultra-rush UpD, probably for safety reasons [27]. Currently all centres in Poland (vs. 92\% in 2009) [14] use MD of $100 \mu \mathrm{g}$, similarly to practices in France ( $96 \%$ centres) and in the UK (89\% vs. 98\%) [13, $15,16]$. The most frequent time interval between subsequent MDs is 4 weeks, what is partially compliant with the guidelines which suggest to progressively prolong the interval after the first year of treatment. Our questionnaire did not contain such answer option.

Also a high congruence with the recommendations concerns the VIT treatment time of 3 to 5 years, with the preference for the upper limit $[6,12]$. In Poland, 5 years of treatment predominates (now $68 \%$ vs. $73 \%$ in 2009 , respectively). In France, half of practitioners treated patients for 5 years [16], while in the UK, probably for the economic reasons, currently 3 years' treatment is mainly practiced ( $83 \%$ of all VIT practitioners vs. $55 \%$ previously) $[13,15]$. In Poland, the longer VIT duration is usually applied in case of patients with mastocytosis, while only one fourth of Polish centres extend VIT duration in case of the elevated bsT in patients without mastocytosis. All recommendations propose that a longer period or lifelong treatment should be considered in patients with a high risk of relapses - severe initial sting reactions and systemic side-effects during VIT, both the most frequent in mastocytosis patients, as well as in the bee venom allergic ones [4, 6, 8, 12].

\section{Assessment of treatment effectiveness before its termination}

Both previous and current EAACI guidelines state that size of positive skin test reactions, as well as slgE concentrations have a limited predictive value with regard to long-term protection after VIT. However, if both skin tests and slgE become negative, VIT may be stopped after 3 years [6]. Currently, at VIT termination about $40 \%$ of Polish centres perform skin tests and almost $60 \%$ perform slgE (vs. $46 \%$ in previous study) [14], which is two times higher than in the UK $30 \%$ in 2014 vs. 50\% in 2008) $[13,15]$. Our data are similar to French data where almost two thirds of practitioners check slgE at the end of treatment [16]. Positive results influence decisionmaking in all countries, meaning longer than standard treatment time in Poland (now about $30 \%$ vs. $20 \%$ previously), in the UK (now 5\% vs. $22 \%$ in 2008), in France almost half [13-16]. Though with the respect to the last guidelines, combined with the economic reasons, neither skin testing results nor specific IgE are recommended at the termination of treatment. Evaluation of IgG4 level during VIT or before its termination, is not recommended by the guidelines $[6,12]$, but it is still practiced in Poland by about $10 \%$ of centres; this value has increased from $8 \%$ to $13 \%$ [14]. The reason may be the belief of some authors that IgG4 can serve as a marker of successful VIT, while it seems rather to be a marker of exposure [28, 29]. In the UK, monitoring VIT by means of $\mathrm{IgG}_{4}$ antibodies was never applied $[13,15]$, while in France it was done by $5 \%$ of practitioners [16].

Sting challenge (SC) is regarded as the most relevant marker of successful VIT treatment, followed by a reaction to a natural field sting as both indicate the tolerance and immunoprotection [30, 31]. In Poland, SC remains still rarely available in practice as about $75 \%$ of centres (vs. $50 \%$ out of 26 centres in 2009) did not perform it at all. Its rare application is mainly due to practical aspects and experience limitations [14]. In the UK, according to the previous audit, almost all centres did not practice the SC, whereas currently such data are unavailable, similarly for France $[13,15,16]$.

\section{Medication}

Self-medication in HVA patients with systemic reactions in the past, is crucial and remains an important part of the patient's education in view of the guidelines. Recently, an EAACI position paper on this topic has been published [32]. Real-life practice is highly compliant with the guidelines and currently most Polish centres prescribed adrenaline auto-injectors (AAI) either regardless of severity of the systemic reaction to all patients with mastocytosis and these referred for diagnosis, or for those with a history of reactions of at least 2 to 4 grades in Mueller's scale. What is important to note is that still half of the centres prescribe AAl to all patients following the termination of treatment, as they did pre VIT. This may show either doctors' medico-legal fear or their doubts in the successful immunoprotection following VIT, in spite of its documented high therapeutical effectiveness achieved after 5 years of treatment (approximately 90-100\% in wasp venom allergy and approximately $80 \%$ in bee venom allergy) [33-35]. Questions regarding the AAI prescription following VIT treatment were neither included in the questionnaire previously used in Poland, nor by the British or French authors [13-16]. 
Both, previous and current EAACI guidelines recommend antihistamine premedication to reduce the number and severity of large local reactions as well as mild dermal (urticaria, angioedema) systemic reactions [6, 12]. Currently in Poland, antihistamine premedication is used less commonly in comparison to our previous study, regardless of the reason: in all patients (55\% vs. $73 \%$ ), in those with local reaction to VIT (39\% vs. $46 \%)$, as well as in case of systemic reactions during VIT (7\% vs. 27\%) [14]. Stable values of antihistamine premedication are reported in the UK. Routine application of the medication is conducted by $40 \%$ of respondents in all VIT-treated patients $[13,15]$, similarly to France, where premedication has been used systematically or occasionally by less than half of practitioners ( $42 \%$ vs. $30 \%$, respectively) [16].

The previous EAACI guidelines strongly encouraged to discontinue $\beta$-blockers and ACE-inhibitors in VIT-treated patients [6]. The current body of evidence indicates that anaphylaxis does not occur more frequently in patients receiving $\beta$-blockers, but the older population with cardiovascular comorbidities are at an increased risk of more severe systemic reactions, and weak response to adrenaline intervention. It seems also that the risk of ACEI continuation might be overestimated, leaving the problem within the narrow group of certain patients with cardiovascular comorbidities [36]. The safety of cardiovascular treatment along with VIT is also indicated in the Polish real-life study [37]. Our data show that less than half of the Polish centres discontinued $\beta$-blockers and less than a quarter did so for ACEI (Table 4). In the UK, much more centres, than in Poland, decide to drop both $\beta$-blockers (62\%) and ACEI (78\%) [15].

\section{Differences in health system organization can influence procedures}

Due to the differences in the health system organization between the European countries, there is a methodological difference in the way the surveys were conducted. In Poland, VIT is performed only by allergy specialists in allergy centres. Hence, the respondents of our study were allergologists, one per centre. For this reason, we obtained responses from almost all centres dealing with HVA; therefore, the presented results are very close to real numbers. Whereas in both French and British studies, respondents were individual doctors involved in VIT practice $[13,15,16]$. In the UK, VIT is conducted by either allergists or immunologists, while in France by allergy, pneumonology or dermatology specialists as well as by paediatricians $[13,15,16]$. Additionally, VIT in Poland is exclusively performed at the secondary and tertiary level. The electronic way of questionnaire completion could have also improved the response rate. We may assume that financing and health care structures differ across these three countries. This may have a major impact on the setting (out-patient vs. in-patient) of treatment as well as the kind of the protocol administered. Health system organization seems to influence the doctor's involvement, protocol preference and locations of procedure, what we have already indicated in our previous studies [14]

As a limitation of our questionnaire, we should indicate two areas which were omitted: safety matters, investigated by British authors [13] and the selection of patients to VIT, investigated by the French authors [16].

\section{Differences in the EAACI guidelines 2005 vs. 2017 with respect to Polish real-life practice}

The newest evidence-based EAACI VIT guidelines are for the first time produced using the Appraisal of Guidelines for Research \& Evaluation (AGREE II) approach, to guarantee the most objective current knowledge [38]. Table 4 presents a summary of the real-life Polish practices in a comparison to the 2005 and 2017 guidelines and shows the updated recommendations; some which were only slightly changed and others which were fully reformulated after 12 years $[6,12]$.

\section{Conclusions}

The audit is an indispensable tool to verify compliance with recommendations in everyday practice. In the most important procedures, in Poland we have obtained a very high compliance with the guidelines, which shows that Polish specialists are well educated regarding VIT. Nevertheless, we have also observed a large spread of results in these areas where the guidelines are not precisely defined. Inclusion of all stages of treatment and more regular updates of guidelines would facilitate the unification of the medical procedures.

\section{Acknowledgments}

Authors thank all respondents, being members of Immunotherapy Section of Polish Society of Allergology Working Group: Zbigniew Bajor, Zbigniew Bartuzi, Anna Bodzenta-Łukaszyk, Elżbieta Borucka, Piotr Z. Brewczyński, Anna Bręborowicz, Andrzej Dąbrowski, Radosław Gawlik, Grzegorz Gąszczyk, Marek Jutel, Marek Kowalski, Jerzy Kruszewski, Piotr Kuna, Michał Kurek, Artur Kwaśniewski, Joanna Lange, Teresa Małaczyńska, Elżbieta Matusz, Marek Niedoszytko, Katarzyna Olejniczak, Marek Józef Paśnicki, Jolanta PietraszekMamcarz, Grażyna Pulka, Marta Rachel, Barbara Rogala, Magdalena Rzeszutko-Grabowska, Marcin Stobiecki, Ewa Świebocka, Ewa Trębas-Pietraś, Magdalena Zakrzewska, Aleksander Zakrzewski, Janusz Zaryczański, Małgorzata Żurowska-Gębała.

English proofreader - Matylda Gawor.

\section{Conflict of interest}

The authors declare no conflict of interest. 


\section{References}

1. Portnoy JM, Moffitt JE, Golden DB, et al. Stinging insect hypersensitivity: a practice parameter. The Joint Force on Practice Parameters, the American Academy of Allergy, Asthma and Immunology, the American College of Allergy, Asthma and Immunology, and the Joint Council of Allergy, Asthma and Immunology. J Allergy Clin Immunol 1999; 103: 963-80.

2. Moffitt JE, Golden DB, Reisman RE, et al. Stinging insect hypersensitivity: a practice parameter update. J Allergy Clin Immunol 2004; 114: 869-86.

3. Golden DB, Moffitt J, Nicklas RA, et al. Stinging insect hypersensitivity: a practice parameter update 2011. J Allergy Clin Immunol 2011; 127: 852-54.

4. Golden DB, Demain J, Freeman T, et al. Stinging insect hypersensitivity: a practice parameter update 2016. Ann Allergy Asthma Immunol 2017; 118: 28-54.

5. Bousquet J, Müller UR, Dreborg S, et al. Immunotherapy with hymenoptera venoms. Position paper of the Working Group on Immunotherapy of the European Academy of Allergy and Clinical Immunology. Allergy 1987; 42: 401-13.

6. Bonifazi F, Jutel M, Biló BM, et al.; EAACl Interest Group on Insect Venom Hypersensitivity. Prevention and treatment of hymenoptera venom allergy: guidelines for clinical practice. Allergy 2005; 60: 1459-70.

7. Jutel M, Kowalski M, Kruszewski J, et al. Standards in allergology part IV. Specific allergen immunotherapy. Allergol Rev 2005; 2: 43-9.

8. Krishna MT, Ewan PW, Diwakar L, et al. Diagnosis and management of hymenoptera venom allergy: British Society for Allergy and Clinical Immunology (BSACI) guidelines. Clin Exp Allergy 2011; 41: 1201-20.

9. Pfaar O, Bachert C, Bufe A, et al. Guideline on allergen-specific immunotherapy in IgE-mediated allergic diseases. Allergo J Int 2014; 23: 282-319.

10. Musarra A, Bilò MB, Bonini S, et al. Consensus on allergen specific immunotherapy. Eur Ann Allergy Clin Immunol 2013, 45 (Suppl 3): 5-53.

11. Dhami S, Zaman H, Varga EM, et al. Allergen immunotherapy for insect venom allergy: a systematic review and meta-analysis. Allergy 2017; 72: 342-65.

12. Sturm GJ, Varga EM, Roberts G, et al. EAACI Guidelines on allergen immunotherapy: Hymenoptera venom allergy. Allergy 2018; 73: 744-64.

13. Diwakar L, Noorani S, Huissoon AP, et al. Practice of venom immunotherapy in the United Kingdom: a national audit and review of literature. Clin Exp Allergy 2008; 38: 1651-8.

14. Cichocka-Jarosz E, Diwakar L, Brzyski P, et al. Congruence of the current practices in hymenoptera venom allergic patients in Poland with EAACl guidelines. Arch Med Sci 2011; 7: 832-9.

15. Diwakar L, Ewan P, Huber PA, et al. The impact of national guidelines on venom immunotherapy practice in the United Kingdom. Clin Exp Allergy 2016; 46: 749-53.

16. Dzviga C, Matevi C, Bonniaud P, et al. Survey on practice of venom immunotherapy in France. Arch Med Sci 2016; 12: 150-5.

17. Professional online surveys with LimeSurvey. LimeSurvey official website. https://www.limesurvey.org. Accessed 2015.11.16.

18. Bilò BM, Bonifazi F. Epidemiology of insect-venom anaphylaxis. Curr Opin Allergy Clin Immunol 2008; 8: 330-7.

19. Roll A, Hofbauer G, Weber BK, Schmid-Grendelmeier P. Safety of specific immunotherapy using a four-hour ultra-rush induction scheme in bee and wasp allergy. J Invest Allergol Clin Immunol 2006; 16: 79-85.

20. Pasaoglu G, Sin BA, Misirligil Z. Rush hymenoptera venom immunotherapy is efficacious and safe. J Invest Allergol Clin Immunol 2006; 16: 232-8.
21. Sánchez-Machín I, Moreno C, González R, et al. Safety of a 2-visit cluster schedule of venom immunotherapy in outpatients at risk of life threatening anaphylaxis. J Invest Allergol Clin Immunol 2010; 20: 89-92.

22. Nittner-Marszalska M, Cichocka-Jarosz E, Małaczyńska T, et al. Safety of ultrarush venom immunotherapy: comparison between children and adults. I Invest Allergol Clin Immunol 2016; 26: 40-7.

23. Asaria M, Dhami S, van Ree R, et al. Health economic analysis of allergen immunotherapy for the management of allergic rhinitis, asthma, food allergy and venom allergy: a systematic overview. Allergy 2018; 73: 269-83.

24. Jutel M, Skrbic D, Pichler WJ, Müller UR. Ultra rush bee venom immunotherapy does not reduce cutaneous weal responses to bee venom and codeine phosphate. Clin Exp Allergy 1995; 25: 1205-10.

25. Birnbaum J, Ramadour M, Magnan A, Vervloet D. Hymenoptera ultra-rush venom immunotherapy (210 $\mathrm{min}$ ): a safety study and risk factors. Clin Exp Allergy 2003; 33: 58-64.

26. Alvarez-Cuesta E, Bousquet J, Canonica GW, et al. Subcutaneous immunotherapy. Appendix I. Allergy 2006; 61 (Suppl 82): 18.

27. Ruëff F, Wolf H, Schnitker J, et al. Specific immunotherapy in honeybee venom allergy: a comparative study using aqueous and aluminium hydroxide adsorbed preparations. Allergy 2004; 59: 589-95.

28. Saulite I, Hoetzenecker W, Guenova E, et al. Skin test reactivity to Hymenoptera venom after venom immunotherapy correlates inversely with the IgG/lgE ratio. Int Arch Allergy Immunol 2017; 174: 190-9.

29. Schiener M, Graessel A, Ollert M, et al. Allergen-specific immunotherapy of Hymenoptera venom allergy - also a matter of diagnosis. Hum Vaccin Immunother 2017; 13: 2467-81.

30. Ruëff F, Przybilla B, Müller U, Mosbech $H$. The sting challenge test in hymenoptera venom allergy. Position paper of the Subcommittee on Insect Venom Allergy of the European Academy of Allergology and Clinical Immunology. Allergy 1996; 51: 216-25.

31. Nittner-Marszalska M, Bant A, Bodzenta-Łukaszyk A, et al. Insect-sting challenge in patients with hymenoptera venom allergy. Polish Allergy Society Expert Group Position Paper. Allergy Asthma Immunol 2010; 15: 134-8.

32. Bilò MB, Cichocka-Jarosz E, Pumphrey R, et al. Self-medication of anaphylactic reactions due to hymenoptera stings-an EAACI Task Force Consensus Statement. Allergy 2016; 71: 931-43.

33. Müller U, Helbling A, Berchtold E. Immunotherapy with honeybee venom and yellow jacket venom is different regarding efficacy and safety. J Allergy Clin Immunol 1992; 89: 529-35.

34. Ruëff F, Przybilla B. Venom immunotherapy: adverse reactions and treatment failure. Curr Opin Allergy Clin Immunol 2004; 4: 307-11.

35. Stritzke AI, Eng PA. Age-dependent sting recurrence and outcome in immunotherapy-treated children with anaphylaxis to hymenoptera venom. Clin Exp Allergy 2013; 43: 950-5.

36. Stoevesandt J, Hosp C, Kerstan A, Trautmann A. Hymenoptera venom immunotherapy while maintaining cardiovascular medication: safe and effective. Ann Allergy Asthma Immunol 2015; 114: 411-6.

37. Kołaczek A, Skorupa D, Antczak-Marczak M, et al. Safety and efficacy of venom immunotherapy: a real life study. Adv Dermatol Allergol 2017; 34: 159-67.

38. Molino CGRC, Ribeiro E, Romano-Lieber NS, et al. Methodological quality and transparency of clinical practice guidelines for the pharmacological treatment of non-communicable diseases using the AGREE II instrument: a systematic review protocol. Syst Rev 2017; 6: 220. 